\title{
Retracted: Correlation of CCNA1 Promoter Methylation with Malignant Tumors: A Meta-Analysis Introduction
}

\author{
BioMed Research International \\ Received 17 December 2020; Accepted 17 December 2020; Published 19 February 2021 \\ Copyright (c) 2021 BioMed Research International. This is an open access article distributed under the Creative Commons \\ Attribution License, which permits unrestricted use, distribution, and reproduction in any medium, provided the original work \\ is properly cited.
}

BioMed Research International has retracted the article titled "Correlation of CCNA1 Promoter Methylation with Malignant Tumors: A Meta-Analysis Introduction" [1]. This article is one of a series of very similar meta-analyses written by different authors that were published in 2014 and 2015, characterized by the use of particular phrases [2]. The articles have the same structure, with the figures in the same order. The appearance of the figures and parts of the text are also similar.

The article is being retracted with the agreement of the journal and the editorial board due to concerns regarding the reliability of the data. Despite numerous attempts, the authors could not be contacted to provide a response to these concerns.

\section{References}

[1] B. Yang, S. Miao, L.-N. Zhang, H.-B. Sun, X. Zhe-Nan, and C.S. Han, "Correlation of CCNA1 Promoter Methylation with Malignant Tumors: A Meta-Analysis Introduction," BioMed Research International, vol. 2015, Article ID 134027, 12 pages, 2015.

[2] G. Filion, "A flurry of copycats on PubMed," The Grand Locus, 2014, http://blog.thegrandlocus.com/2014/10/a-flurry-ofcopycats-on-pubmed. 